\title{
KONDISI PERUSAHAAN PERIKANAN DI KOTA BITUNG PASCA MORATORIUM 2014
}

Evan Sparta Sarempaa ${ }^{1}$; Eddy Mantjoro ${ }^{2}$; Vonne Lumenta ${ }^{2}$

1) Mahasiswa Fakultas Perikanan dan IImu Kelautan Universitas Sam Ratulangi, Manado.

2) Staff Pengajar Fakultas Perikanan dan IImu Kelautan Universitas Sam Ratulangi, Manado. Koresponden email: evanspartasarempaa@gmail.com

\begin{abstract}
North Sulawesi is one of the provinces in Indonesia which have large fisheries potential. The province has made the results of operations and marine fisheries as one of the featured products to spur increase revenue. Then formulated some questions that become problems in this study 1). How is the post-moratorium fishing company in Bitung 2). Is this moratorium policy implementation can enhance the progress of the fishing company in Bitung 3). How do enterprise solutions to meet the needs of the company, when applied moratorium on fishing in Bitung. This study aims to 1). To obtain scientific data about the condition of the fishing company Post moratorium on fishing in Bitung 2) .To determine the effect of the implementation of the moratorium policy of the condition of the fishing company in Bitung. The method used in this research case study approach. Retrieval of data taken in two fishing companies, namely PT. Sari Tuna Makmur and PT. Blue Ocean Grace International in Bitung City District of Aertembaga, data collection is done by observation and in-depth interviews. 1.Conditions fishing company in Bitung post-moratorium by the Minister of Marine and Fisheries in November 2014 are as follows: a) The number of vessels decreased from 3,213 in 2014 to 2,222 in 2015 and then rose to 3,165 in 2016. b) Production of fish reduced from 111,315.53 in 2014 to 45208.52 in 2015 then production rises, namely 46522.77 2016. c) The increase in the market price of skipjack Winenet, Girian and TPI of the normal price 12500-14000, in 2014 rose to 17000-20000 in 2015 and 2016. As for the Tuna from the standard price of 32000-35000 in 2014 and rose to 50000-55000 in 2015 and 2016. Then for the fish Deho from 5000-8000 at the normal price in 2014, rose to 9000-12000 in 2015, and rose to 12,000-15,000 in 2016. d) Increased export of fishery company PT. STM of 196,034.50 in 2014 to 294,911.4 in 2015 and falling back to 200,403.95 in 2016. e) The increase in exports of fishery company PT. Bogi of 116,196.20 in 2015 to 285,797.3 in 2016. 2. Moratorium Policy turn out to be a positive impact on the company's progress fishery indicated by the decline in the economic sector in Bitung. 3. It was not able to improve the progress of the fishing company in the city of Bitung in general and in particular. 1. moratorium greatly affect the fishing company therefore Policy Minister about the moratorium should be revoked. 2. This study still needs further research is therefore suggested that interested readers can conduct advanced research.
\end{abstract}

Keywords: pole and line, development, capture fishery, fisherman assessment

Abstrak

Kata kunci: huhate, pengembangan, perikanan tangkap, penilaian nelayan

\section{PENDAHULUAN}

Indonesia merupakan negara maritim terbesar di dunia dengan garis pantai terpanjang nomor dua setelah Kanada yaitu $81.000 \mathrm{~km}$. Luas wilayah teritorial Indonesia sebesar 7,1 juta $\mathrm{km}^{2}$ didominasi oleh wilayah laut yaitu kurang lebih 5,4 juta $\mathrm{km}^{2}$. Oleh karena itu, Indonesia memiliki potensi sumber daya ikan melimpah dan tersebar disebagian besar Indonesia (Kenanga, 2012).

Sulawesi Utara adalah salah satu provinsi di Indonesia yang memiliki potensi perikanan yang besar. Provinsi ini telah menjadikan hasil usaha perikanan dan kelautan sebagai salah satu produk unggulan untuk memacu meningkatkan pendapatan asli daerah (Pangemanan, 2015). Dengan mengetahui potensi sumber daya perikanan yang besar maka Pemerintah menetapkan sub sektor perikanan merupakan salah satu motor penggerak pembanguanan (Kenanga, 2012).

Sektor perusahaan yang dominan di Kota Bitung masih berkaitan dengan sektor perikanan, karena banyak perusahaan yang memanfaatkan bahan baku ikan yakni perusahaan pengolahan ikan baik perusahaan skala besar (pabrik) maupun kecil (industri rumah tangga). Sektor transportasi juga masih terkait dengan sektor perikanan khususnya mengangkut hasil perikanan. 
Perikanan yang tangguh akan sangat menunjang peningkatan ekonomi sehingga dapat memenuhi kebutuhan masyarakat terhadap bahan pangan sehingga terpenuhinya bahan mentah untuk perusahaan. Disamping itu, dapat juga meningkatkan kualitas sumber daya manusia, karena Kota Bitung mempunyai posisi lintas jalur migrasi ikan dari samudra pasifik sehingga potensi ikan melimpah (Apsari, 2009).

\section{Perumusan Masalah}

Sektor perusahaan yang dominan di Kota Bitung masih berkaitan dengan sektor perikanan, oleh karena itu dirumuskan beberapa pertanyaan yang menjadi permasalahan dalam penelitian ini.

1. Bagaimana kondisi perusahaan perikanan pasca moratorium di Kota Bitung?

2. Apakah penerapan kebijakan moratorium ini dapat meningkatkan kemajuan perusahaan perikanan di Kota Bitung?

3. Bagaimana solusi yang dilakukan perusahaan untuk memenuhi kebutuhan perusahaan, ketika diterapkan kebijakan moratorium perikanan di Kota Bitung.

\section{Tujuan Penelitian}

Penelitian ini dilakukan untuk mencapai tujuan sebagai berikut :

1. Untuk mendapatkan data ilmiah tentang kondisi perusahaan perikanan Pasca moratorium perikanan di Kota Bitung,

2. Untuk mengetahui pengaruh penerapan kebijakan moratorium terhadap kondisi perusahaan perikanan di Kota Bitung.

\section{Manfaat Penelitian}

1. Sebagai sarana untuk menerapkan ilmu pengetahuan yang telah diperoleh selama kuliah melalui penelitian yang dilakukan langsung dilapangan.

2. Sebagai acuan pustaka dalam melakukan penelitian pada tempat yang sama dilain waktu.

3. Sebagai bahan informasi bagi instansi terkait untuk mengetahui Kondisi Perusahaan Perikanan di Kota Bitung Pasca Moratorium 2014.

4. Untuk mencari solusi yang dilakukan perusahaan perikanan dalam memenuhi kebutuhan ketika diterapkan kebijakan moratorium di Kota Bitung.

\section{Tempat dan Waktu Penelitian}

Tempat penelitian dilakukan di Kota Bitung, waktu yang digunakan dalam penelitian mulai dari konsultasi sampai dengan pelaksanaan ujian \pm 6 bulan, dari bulan Februari sampai dengan bulan Juli 2017.

\section{METODOLOGI PENELITIAN Metode Dasar Penelitian}

Metode adalah cara kerja yang bersistem dan teratur untuk memudahkan pelaksanaan suatu kegiatan guna mencapai tujuan yang ditentukan. Sedangkan penelitian adalah pemeriksaan yang teliti, penyelidikan, kegiatan pengumpulan, pengolahan, analisis, dan penyajian data yang dilakukan secara sistematis dan objektif untuk memecahkan suatu persoalan atau menguji suatu hipotesis untuk mengembangkan prinsip-prinsip umum.

\section{Metode Pengambilan Data}

Metode yang digunakan dalam penelitian ini adalah pendekatan studi kasus. Menurut Mantjoro (1980), studi kasus adalah penelitian yang dilakukan secara terfokus pada suatu kasus tertentu untuk diamati dan dianalisis secara cermat sampai tuntas. 
Tabel. Jumlah Kecamatan, Kelurahan dan Luas Wilayah Kota Bitung

\begin{tabular}{|c|l|r|r|c|}
\hline No. & \multicolumn{1}{|c|}{ Kecamatan } & Kelurahan & Luas Daerah (ha) & $\%$ \\
\hline 1. & Ranowulu & 11 & $15.756,80$ & 50,26 \\
2. & Matuari & 8 & $3.396,00$ & 10,83 \\
3. & Girian & 7 & 516,55 & 1,65 \\
4. & Madidir & 8 & $2.083,00$ & 6,64 \\
5. & Maesa & 8 & 969,70 & 3,09 \\
6. & Aertembaga & 10 & $3.309,30$ & 10,56 \\
7. & Lembeh Selatan & 7 & $2.553,00$ & 8,14 \\
8. & Lembeh Utara & 10 & $2.766,00$ & 8,82 \\
\hline & & 69 & $31.350,35$ ha & 100 \\
\hline
\end{tabular}

Sumber : DKP Kota Bitung, 2017

Luas Wilayah Kecamatan di Kota Bitung

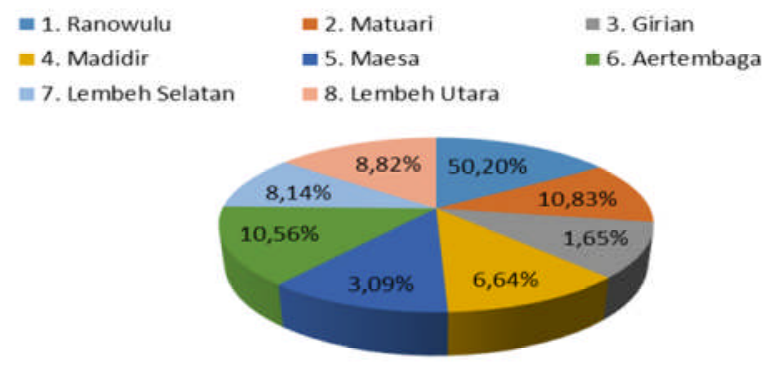

$\overline{\text { Gambar. Diagram Luas Wilayah Kecamatan di Kota Bitung }}$

\section{Penduduk Menurut Jenis Kelamin}

Jumlah penduduk yang ada di Kota Bitung menurut jenis kelamin secara keseluruhan berjumlah 255.340 jiwa, laki-laki 125.074 jiwa dan perempuan 123.773 jiwa.

Tabel. Jumlah Penduduk Kota Bitung Menurut Jenis Kelamin

\begin{tabular}{|l|l|l|l|l|}
\hline Kecamatan & Laki-laki & Perempuan & Jumlah & Persentase (\%) \\
\hline Maesa & 25.243 & 23.543 & 48.786 & $19,11 \%$ \\
\hline Madidir & 21.644 & 20.966 & 42.610 & $16,69 \%$ \\
\hline Girian & 21.194 & 20.233 & 41.427 & $16,22 \%$ \\
\hline Matuari & 20.825 & 19.630 & 40.455 & $15,84 \%$ \\
\hline Aertembaga & 18.849 & 17.333 & 36.182 & $14,17 \%$ \\
\hline Ranowulu & 11.834 & 11.061 & 22.895 & $8,97 \%$ \\
\hline Lembeh Selatan & 6.494 & 5.814 & 12.308 & $4,82 \%$ \\
\hline Lembeh Utara & 5.485 & 5.192 & 10.677 & $4,18 \%$ \\
\hline Jumlah & 125.074 & 123.773 & 255.340 & $100 \%$ \\
\hline
\end{tabular}

Sumber: DKPS Bitung Dalam Angka, 2017 


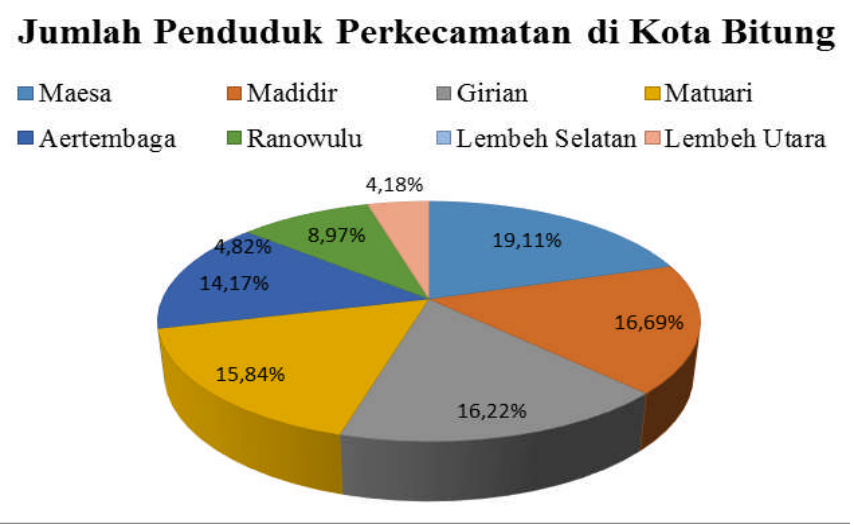

Gambar. Diagram Jumlah Penduduk Per Kecamatan di Kota Bitung

\section{Nelayan Menurut Alat Tangkap}

Nelayan yang ada di Kota Bitung merupakan nelayan yang mempunyai jumlah nelayan dan alat tangkap yang berbeda-beda termasuk alat tangkap yang tradisional dan alat tangkap yang modern, tabel di bawah ini mejelaskan tentang kedua jenis alat tangkap dan jumlah nelayan dalam satu kapal.

Tabel. Jumlah Nelayan Menurut Alat Tangkap

\begin{tabular}{|r|l|r|r|}
\hline \multirow{2}{*}{ No } & \multicolumn{1}{|c|}{ Alat Tangkap } & \multicolumn{2}{|c|}{ Jumlah Nelayan/Tahun } \\
\cline { 3 - 4 } & & 2014 & 2015 \\
\hline 1 & Pancing Ulur (Tuna Hand Line) & 5.975 & 4.174 \\
\hline 2 & Kapal Pengangkut & 1.130 & 614 \\
\hline 3 & Kapal Lampu & 726 & 438 \\
\hline 4 & Rawai Tuna (Long Line) & 475 & 45 \\
\hline 5 & Huhate (Pole and Line) & 375 & 625 \\
\hline 6 & Jaring Insang (Gill Net) Hanyut Oceanik & 475 & 625 \\
\hline 7 & Pukat Cincin (Purse Seine) Pelagis Kecil (PK) & 3.728 & 600 \\
\hline 8 & Pukat Ikan & 180 & 3.660 \\
\hline 9 & Pancing Rawai Dasar (Bottom Long Line) & 50 & 40 \\
\hline & Jumlah & 13.144 & 10.821 \\
\hline
\end{tabular}

Sumber DKP Kota Bitung, 2017

\section{Perkembangan Produksi}

Produksi bertujuan memenuhi kebutuhan manusia, kemakmuran dapat tercapai jika tersedia barang dan jasa dalam jumlah yang mencukupi. Orang atau perusahaan yang menjalankan suatu proses produksi disebut Produsen, dan di bawah ini merupakan produksi perikanan yang ada di Kota Bitung.

Tabel. Produksi Perikanan Kota Bitung

\begin{tabular}{|l|c|c|c|c|c|}
\hline \multirow{2}{*}{ Cabang Usaha } & \multicolumn{5}{|c|}{ Volume Produksi Perikanan Pertahun } \\
\cline { 2 - 6 } & 2012 & 2013 & 2014 & 2015 & 2016 \\
\hline Perikanan Tangkap & $159.319,4$ & $133.227,5$ & $124.501,5$ & $49.441,3$ & $49.834,4$ \\
\hline Kolam & 164 & 443,4 & 496,8 & 502,8 & 535,2 \\
\hline Laut & 32 & 112 & 178,1 & 149,7 & 212,1 \\
\hline J u m I a h & $159.515,4$ & $133.782,9$ & $125.176,4$ & $50.093,80$ & $50.581,7$ \\
\hline
\end{tabular}

Sumber : Dinas Kelautan dan Perikanan Kota Bitung, 2017 
Paparan data pada tabel di atas tentang produksi perikanan Kota Bitung memberikan gambaran bahwa volume produksi perikanan tangkap mengambarkan terjadi penurunan volume produksi di setiap tahunnya. Sebab pada tahun 2014 dan tahun 2016 jelas karena pengaruh penerapan kebijakan Menteri tentang moratorium diberlakukan untuk nelayan yang melakukan penangkapan, sedangkan untuk usaha pembudidaya di kolam terjadi peningkatan volume produksi karena tidak terpengaruh oleh kebijakan Menteri tentang moratorium tersebut, demikian halnya dengan budi daya laut terjadi pula peningkatan volume produksi dari tahun 2012 sampai tahun 2016 karena tidak terimbas oleh kebijakan menteri perikanan dan kelautan yang diresmikan pada bulan November 2014.

Tabel. Produksi Pasokan Bahan Baku Perusahaan Perikanan

\begin{tabular}{|l|c|c|c|}
\hline \multirow{2}{*}{ Nama Perusahaan } & \multicolumn{3}{c|}{ Produksi Bahan Baku/ Volune (Kg) } \\
\cline { 2 - 4 } & 2014 & 2015 & 2016 \\
\hline PT. Sari Tuna Makmur & - & $537.733,70$ & $595.534,05$ \\
\hline PT. Blue Grace Ocean International & $50.000,00$ & $374.000,00$ & $138.000,00$ \\
\hline
\end{tabular}

Sumber : Data Primer, 2017

Pasokan bahan baku ikan merupakan bahan yang sangat penting bagi perusahaan perikanan, dan tabel di atas merupakan jumlah pasokan ikan yang masuk di perusahaan PT. STM tiap tahunnya yaitu $537.733,7 \mathrm{~kg}$ pada tahun 2015 mengalami kenaikan yaitu $595.543,05 \mathrm{~kg}$ pada tahun 2016. Sedangkan untuk PT. BOGI hanya $50.000 \mathrm{~kg}$ pada tahun 2014 karena perusahaan ini didirikan pada bulan Oktober tahun 2014 dan jumlah hasil produksi masih kurang, dan mengalami kenaikan volume yaitu $374.000 \mathrm{~kg}$ pada tahun 2015, kemudian turun kembali menjadi $138.000 \mathrm{~kg}$ pada tahun 2016.

\section{Perkembangan Ekspor}

Ekspor merupakan kegiatan utama dalam perusahaan untuk memacu pertumbuhan ekonomi. Produk perikanan yang ada di perusahaan merupakan salah satu andalan ekspor Kota Bitung karena lokasi ini memiliki infrastruktur yang mendukung bongkar muat barang dari dan ke Kota Bitung dan Pelabuhan Perikanan Samudera (PPS) Bitung. Salah satu variabel yang diteliti ialah perkembangan ekspor yang dikirim melalui pelabuhan Bitung.

Tabel. Perkembangan Ekspor Perikanan Pertahun di Kota Bitung

\begin{tabular}{|c|c|c|c|c|c|c|}
\hline \multirow{2}{*}{$\begin{array}{c}\text { Ekspor } \\
\text { Perikanan }\end{array}$} & $2014(1)$ & $\%$ & $2015(2)$ & $\%$ & $2016(3)$ & $\%$ \\
\cline { 2 - 8 } Ikan Kaleng & $35.989 .981,82$ & 82,72 & $26.899 .853,32$ & 90,35 & $22.752 .413,07$ & 84,62 \\
\hline Ikan Beku & $4.176 .633,12$ & 9,60 & $1.166 .801,30$ & 3,92 & $1.863 .816,33$ & 6,93 \\
\hline Ikan Kayu & $3.341 .931,58$ & 7,68 & $1.707 .661,75$ & 5,74 & $2.270 .844,94$ & 8,45 \\
\hline Jumlah & $43.508 .546,52$ & $100 \%$ & $29.774 .316,37$ & $100 \%$ & $26.887 .074,34$ & $100 \%$ \\
\hline
\end{tabular}

Sumber : Dinas Perindustrian dan Perdagangan Kota Bitung 2017

Pada tabel di atas memberikan gambaran bahwa volume ekspor ikan kaleng pada tahun 2014 terjadi penurunan secara terus menerus sampai 
pada tahun 2016, berbeda dengan volume ekspor ikan beku terjadi peningkatan volume tahun 2014 kemudian menurun pada tahun 2015 dan terjadi kenaikan volume pada tahun 2016, sementara untuk volume eksport ikan kayu pada tahun 2015 mengalami penurunann volume ekspor dan terjadi peningkatan volume ekspor pada tahun 2016. Data pada ketiga grafik memberikan gambaran terjadinya penurunan volume ekspor untuk produk ikan kaleng pada setiap tahunnya sedangkan untuk ikan beku dan ikan kayu mengalami kenaikan volume pada tahun 2016. Keadaan ini sangat berpengaruh bagi perusahaan besar lainnya Ini merupakan dampak dari kebijakan Menteri tentang moratorium dan keadaan alam.

Tabel. Ekspor Perusahaan Perikanan / Tahun di Kota Bitung

\begin{tabular}{|l|l|l|l|}
\hline Nama & \multicolumn{2}{|l|}{ Volume Ekspor (kg) } \\
\cline { 2 - 4 } Perusahaan & 2014 & 2015 & 2016 \\
\hline PT. Sari Tuna Makmur & - & $294.911,4$ & $200.403,95$ \\
\hline PT. Blue Ocean Grace International & - & $116.196,20$ & $74.111,8$ \\
\hline
\end{tabular}

Sumber : Data Primer, 2017

Keadaan produksi ekspor perusahaan perikanan sangat di pengaruhi dari keadaan pasokan ikan yang masuk di perusahaan, dan tiap tahunnya mengalami naik turunnya volume ekspor. PT. STM volume ekspor pada tahun 2014 tidak ada pengesporan, mengalami kenaikan volume ekspor 294.911,4 pada tahun 2015 dan mengalami penurunan kembali menjadi $200.403,95$ pada tahun 2016. Perusahaan PT. BOGI pada tahun 2014 belum ada ekspor perikanan, volume ekspor 116.196,20 pada tahun 2015 mengalami kenaikan menjadi 285.797,3 pada tahun 2016 .

\section{Dampak Kebijakan}

Diberlakukan kebijakan

Kementerian Kelautan dan Perikanan tentang moratorium menyebabkan perikanan di Sulawesi Utara khususnya di Kota Bitung goya, ini dapat dilihat dari beberapa aspek yang terkena dampaknya seperti : berkurannya kegiatan penangkapan di laut, naiknya harga ikan karena produksi menurun, menurunnya jumlah eksport ikan, ratusan buruh pekerja diberhentikan serta sejumlah perusahaan perikanan berhenti beroperasi karena tidak dapat lagi membiayai rumah tangga perusahaan (bangkrut).

\section{Kegiatan Penangkapan}

Aktivitas penangkapan ikan dilakukan dalam upaya untuk memperoleh ikan dilaut dan bukan dilakukan untuk ikan yang dibudidayakan dengan cara apapun yang ada dilaut dengan mengunakan kapal untuk memuat, mengangkut, menyimpan, mendinginkan, menangani, mengolah dan atau mengawetkan ( UU No 45 Tahun 2009 Tentang Perikanan). 
Tabel. Jumlah Kapal beroperasi dan mendaratkan ikan di PPS Kota Bitung

\begin{tabular}{|c|c|c|c|}
\hline \multirow{2}{*}{ Ukuran Kapal } & \multicolumn{3}{|c|}{ Jumlah Kapal/Tahun } \\
\hline & 2014 & 2015 & 2016 \\
\hline$<5 \mathrm{GT}$ & 817 & 477 & 802 \\
\hline$>5-10 \mathrm{GT}$ & 896 & 736 & 888 \\
\hline$>10-20 \mathrm{GT}$ & 195 & 150 & 194 \\
\hline$>20-30 \mathrm{GT}$ & 781 & 591 & 777 \\
\hline$>30-40 \mathrm{GT}$ & 31 & 22 & 29 \\
\hline$>40-50 \mathrm{GT}$ & 11 & 23 & 14 \\
\hline$>50-100 \mathrm{GT}$ & 358 & 230 & 340 \\
\hline$>100-200 \mathrm{GT}$ & 115 & 16 & 112 \\
\hline$>200-300 \mathrm{GT}$ & 9 & - & 7 \\
\hline$>300-400 \mathrm{GT}$ & - & - & 2 \\
\hline$>400-500 \mathrm{GT}$ & - & - & - \\
\hline$>500 \mathrm{GT}$ & - & - & - \\
\hline Jumlah & 3.213 & 2.222 & 3.165 \\
\hline
\end{tabular}

Sumber : DKP Kota Bitung, 2017

Penurunan jumlah kapal penangkapan yang beroperasi dan mendaratkan ikan di PPS Kota Bitung dari 3.213 pada tahun 2014 menurun menjadi 2.222 pada tahun 2015, dan kemudian naik kembali menjadi 3.165 pada tahun 2016, karena dampak kebijakan Menteri Kelautan Perikanan di mulai dari bulan November 2014.

\section{Harga Ikan $(\mathrm{Kg})$}

Semakin banyak jumlah ikan harga ikan akan turun dan permintaan ikan semakin meningkat/banyak. Sebaliknya, semakin berkurang jumlah ikan, maka harga ikan yang dijual akan naik dan permintaan ikan berkurang. Data primer ini di ambil di TPI dan di pasar yang ada di Kota Bitung.

Tabel. Perbandingan Harga Ikan di TPI dan di Pasar Kota Bitung

\begin{tabular}{|l|l|r|r|r|}
\hline \multirow{2}{*}{ Lokasi Pengambilan Data } & \multirow{2}{*}{ Jenis Ikan } & \multicolumn{3}{|c|}{ Harga Ikan per Kg (Rp) } \\
\cline { 2 - 4 } & & \multicolumn{1}{|c|}{2014} & \multicolumn{1}{c|}{2015} \\
\hline \multirow{4}{*}{ TPI Bitung } & Cakalang & $12.500-14.000$ & $17.000-17.500$ & $17.000-20.000$ \\
\cline { 2 - 5 } & Tuna & $32.000-35.000$ & $42.000-50.000$ & $50.000-55.000$ \\
\cline { 2 - 5 } & Deho & $5.000-8.000$ & $9.000-10.000$ & $10.000-11.000$ \\
\hline \multirow{4}{*}{ Pasar Winenet } & Cakalang & $17.000-19.000$ & $17.000-25.000$ & $20.000-25.000$ \\
\cline { 2 - 5 } & Tuna & $29.000-35.000$ & $45.000-50.000$ & $45.000-50.000$ \\
\cline { 2 - 5 } & Deho & $5.000-8.000$ & $10.000-12.000$ & $12.000-14.00$ \\
\hline \multirow{3}{*}{ Pasar Girian } & Cakalang & $18.000-16.000$ & $19.000-25.000$ & $20.000-25.000$ \\
\cline { 2 - 5 } & Tuna & $30.000-35.000$ & $45.000-50.000$ & $50.000-57.000$ \\
\cline { 2 - 5 } & Deho & $7.000-8.000$ & $12.000-15.000$ & $13.000-15.000$ \\
\hline
\end{tabular}

Sumber : Data Primer, 2017 
Kenaikan harga ikan yang ada di TPI dan di Pasar yang ada di Kota Bitung dari tahun 2014 sampai pada tahun 2016 mengalami kenaikan yang sangat tinggi keadaan ini disebabkan berkurangnya produksi ikan dari laut karena jumlah penangkapan ikan berkurang dari nelayan yang berkapasitas > 50 GT dan kondisi ini di pengaruhi oleh kebijakan Menteri tentang moratorium dan keadaan alam.

\section{KESIMPULAN DAN SARAN Kesimpulan}

1. Kondisi perusahaan perikanan di Kota Bitung pasca moratorium oleh Menteri Kelautan dan Perikanan pada bulan November tahun 2014 adalah sebagai berikut :

a) Jumlah kapal berkurang dari 3.213 pada tahun 2014 menjadi 2.222 pada tahun 2015 kemudian naik menjadi 3.165 pada tahun 2016.

b) Produksi ikan berkurang dari 111.315,53 pada tahun 2014 menjadi 45.208,52 pada tahun 2015 kemudian produksinya naik yaitu 46.522,77 pada tahun 2016

c) Meningkatnya harga ikan cakalang di pasar Winenet, Girian dan TPI dari harga normal 12.500-14.000, pada tahun 2014 naik menjadi $17.000-20.000$ pada tahun 2015 dan 2016. Sedangkan untuk ikan Tuna dari harga standar 32.000-35.000 pada tahun 2014 dan naik menjadi 50.000-55.000 pada tahun 2015 dan 2016. Kemudian untuk ikan Deho dari harga normal $5.000-8.000$ pada tahun 2014, naik menjadi 9.000-12.000 pada tahun 2015, dan naik menjadi 12.000-15.000 pada tahun 2016.

d) Meningkatnya ekspor perusahaan perikanan PT. STM dari $196.034,50$ pada tahun 2014 menjadi $294.911,4$ pada tahun 2015 dan turun kembali menjadi 200.403,95 pada tahun 2016.

e) Meningkatnya ekspor perusahaan perikanan PT. BOGI dari 116.196,20 pada tahun 2015 menjadi $285.797,3$ pada tahun 2016.

f) Usaha lain seperti rumah makan dan koperasi ternyata mengalami dampak yang sama berkurang, sehingga terjadi penurunan omset koperasi yaitu 28.200.000 pada tahun 2014 turun menjadi 13.600.000 pada tahun 2015, kemudian meningkat menjadi 30.200.000 pada tahun 2016 dan untuk rumah makan yaitu 15.800 .000 pada tahun 2014 turun menjadi 4.450 .000 pada tahun 2015 dan naik menjadi 30.800.000 pada tahun 2016. Kondisi ini karena dipengaruhi oleh kebijakan Menteri tentang moratorium 2014.

2. Kebijakan Moratorium ternyata tidak dapat memberikan dampak positif terhadap kemajuan perusahaan perikanan yang ditunjukkan oleh penurunan sektor ekonomi di Kota Bitung.

3. Ternyata tidak dapat meningkatkan kemajuan perusahaan perikanan di Kota Bitung pada umumnya dan pada khususnya.

\section{Saran}

1. Kebijakan moratorium sangat mempengaruhi perusahaan perikanan oleh karena itu Kebijakan Menteri 
tentang moratorium tersebut sebaiknya dicabut kembali.

2. Penelitian ini masih memerlukan penelitian lanjutan oleh karena itu disarankan pembaca yang berminat dapat melakukan penelitian lanjutan.

\section{DAFTAR PUSTAKA}

Apsari. 2009. Kontribusi Subsektor Perikanan Terhadap Perkembangan Perekonomian Kota
Bitung Periode 2000-2007. Skripsi Departemen IImu Ekonomi. Bogor: Institut Pertanian Bogor.

Kenanga, DT.2012. Faktor-Faktor Yang Mempengaruhi Pendapan Usaha Perikanan Tangkap Dengan Kapal Motor- Studi Kasus Kota Bitung. Skripsi Fakultas Ekonomi. Yogjakarta: Universitas Atma Jaya

Pangemanan, O, 2015. Dampak Kebijakan Moratorium Terhadap Indusiti Perikanan Studi Kasus Kota Bitung. Skripsi Fakultas Perikanan dan IImu Kelautan. Manado : Universitas Sam Ratulangi. 